\title{
Comparing public perceptions of social work and social workers' expectations of the public view
}

Barbara Staniforth, Kelsey L. Deane and Liz Beddoe University of Auckland, New Zealand

\begin{abstract}
INTRODUCTION: Previous studies have explored public perception of social work and social workers. There is little written about what social workers think about how they, and the profession of social work, are viewed by the public. This article explores the views of a sample of social workers in Aotearoa New Zealand about their beliefs around the public perception of social work and social workers.
\end{abstract}

AIMS: This article aims to explore social worker views on the public perception of social work, and then compares these findings with a previous study which looked at the public perception of social workers.

METHODOLOGY: An online survey was conducted with 403 social workers from the Aotearoa New Zealand Association of Social Work, which asked them about their perceptions on how social work and social workers are viewed by the public. The results are then compared to a previous telephone survey, which asked 386 members of the public their views on social work and social workers.

FINDINGS: Results demonstrate that the social workers generally had a poorer impression of what the public believed in most areas, compared to what the public had indicated in the prior study.

CONCLUSION: Social workers, social work professional bodies and social work educators need to be proactive in promoting accurate information about social work and what social workers do.

KEYWORDS: social work; public perceptions

\section{Introduction}

Understanding how social work and social workers are perceived is of interest for many reasons. It has implications for service delivery, education, job satisfaction and retention, and for the confidence of people using and those referring to services. While previous studies have explored perceptions of social workers from various stakeholder positions, to date, no large-scale studies have explored what social workers believe the public thinks of them or their profession.

This article reports on findings of an analysis of data from two studies. The first study, reported in Staniforth, Fouché and Beddoe (2014), presented the results of a telephone survey of public perceptions. The findings, which included responses from 386 participants, indicated that:
AOTEAROA

NEW ZEALAND SOCIAL WORK 28(1), 13-24.

CORRESPONDENCE TO: Barbara Staniforth b.staniforth@auckland.ac.nz 
1) social work should become more visible;

2) social workers needed to be better at what they do and to demonstrate their effectiveness; and 3) the 'public' appeared to be relatively well informed about what social workers do and what qualifications they require. In completing the analysis of the first study the authors felt that it would be useful to explore how social workers themselves viewed the role of social work in Aotearoa New Zealand, and to obtain their insights on public perceptions of their profession.

The research question for the second study was "How do social workers think that they are perceived by the public of Aotearoa New Zealand?" The second study employed an online questionnaire to survey social workers $(n=403)$ on their perceptions of public opinions, with questions largely matched to the first study, to enable comparisons. This article reports on the data from the social work study on how social workers believe they are perceived by the public, and an analysis undertaken to ascertain if there were significant differences in the previously published public's perceptions of social work and social workers and the subsequently surveyed social workers' expectations of how the public perceive social work and social workers.

\section{Literature review}

The public perception of social work and social workers is varied, complex and multifaceted. The portrayal of social work has been of concern to government funders of social services, social workers and social work bodies for many decades (Pollak, 1961; Condie, Hanson, Lang, Moss, \& Kane, 1978; Aldridge, 1990; Franklin \& Parton, 1991). A few studies have looked at how the public perceives social work; these are briefly discussed here.

A study conducted for the Department of Health (UK) in 2000 (Research Works, 2001) consisted of an analysis of six focus groups undertaken in England. This survey found that participants were not well-informed about the qualifications and training required in order to become a social worker. Rather, they focussed on describing the personal qualities needed to be a social worker, for example "communication skills, patience, impartiality, and inner emotional strength" (p. 5). The researchers noted that this emphasis on personality traits, motivation to 'do good', combined with a lack of awareness of social work as a skilled paid career led most to conclude that social work was a "vocation rather than a profession"(p. 5). Ultimately, social workers were considered to hold a similar status to other helping professions, such as nursing and teaching. A stereotypical image of a social worker consistently emerged as someone young, female "hippyish and idealistic in outlook" (pp. 5-6). Despite these ambivalent views, the work undertaken by social workers was deemed to be worthwhile.

A mixed method study of public knowledge and attitudes about social work in Scotland conducted for the Scottish Executive by Davidson and King (2005) found that while there was good general knowledge about what social workers did, "detailed knowledge about social workers and specifically about the different services they provide and the means by which these can be accessed, was fairly low among significant proportions of research participants" (p. 7). The survey data demonstrated that people were more likely to be positive than negative about social workers by a margin of about 2:1 (Davidson \& King, 2005). Participants in the focus groups described social workers as, 'helpful', 'nice', 'good people' and 'vital' (p. 24). There was a perception that social work is a stressful profession that does not receive sufficient credit for its contribution. Davidson and King reported that in all groups there were spontaneous references to the 'bad press' that social workers receive:

with participants generally feeling that this is perhaps unfair and a reflection of a broader tendency on the part of the 
media to highlight bad rather than good news [and tendency] to focus mainly on the role and perceived culpability of the social worker(s), or case management process (2005, p. 25).

Amongst Davidson and King's participants there was a widespread perception that the media has contributed significantly to negative perceptions of social workers among the public, "The words 'interfering' and 'busy-bodies' were mentioned in most groups, with some feeling that social workers are often inefficient and ineffectual" (Davidson \& King , 2005, p. 24).

Lecroy and Stinson (2004) conducted a random phone survey of 386 members of the public across the USA. They found that those surveyed had a fairly good awareness of what social workers do, and held generally favourable impressions of social work and social workers. This was in contrast to a previous study conducted by Condie, Hanson, Lang, Moss and Kane (1978) which surveyed 250 'householders' in Western USA. Condie et al., (1978) revealed that the public found it difficult to identify many social work roles, and that the role of "child protector" was highly associated with social work. This study also found that $97 \%$ of their respondents would be reluctant to seek help from a social worker if they had personal problems.

A few studies have explored student perceptions of social work. Dennison, Poole, and Qaquish (2007) surveyed 678 students taking various majors at an American state university. Their findings indicated that perceptions and understanding of social work were improved when the participant had had contact with a social worker (not just in a professional capacity, it could be with a family friend etc.) and that there was general consensus that social workers were not well paid. Jones, Vela, Wang and Walden (2006) surveyed 197 undergraduate students at a university in Western USA. Participants were divided into a social work cohort (31.5\%), a psychology cohort (33\%) and a general category (29.9\%). This study found that while the social work cohort was more aware of the roles played by social workers, all groups said that they would prefer to have therapy from a psychologist, and that a psychology degree was thought to be more lucrative than a social work degree. This study also found that there were more negative attitudes reported towards working in statutory agencies such as child protection and probation, and more favorable attitudes towards working with developmentally disabled persons, victim assistance and social work in schools.

There have also been some studies that have surveyed social workers about their perceptions. One study explored how social workers perceived their portrayal in the news and entertainment media (Zugazaga, Surette, Mendez, \& Otto, 2006). In this USA study, $665 \mathrm{MSW}$ qualified social workers, who were from the Florida Chapter of the National Association of Social Work, were surveyed. The social workers were asked to provide ratings on nine different paired adjective scales related to media portrayal ${ }^{1}$. In all instances, they indicated more negative than positive views of the portrayal of social work.

Little research has been conducted in New Zealand although the portrayal and perception of social work in news media has been recognised as a professional issue (Lytollis, 1996; Stanfield \& Beddoe, 2013). A study in New Zealand was conducted by the Social Workers Registration Board (SWRB) in 2011, as part of its review of the Social Workers Registration Act 2003. One of the questions asked in the survey was 'If you were referring a friend or relative to see a professional for help with a personal problem, how much confidence would you have in each of the following professionals to assist them?' This study

These scales included effective/ineffective, normal/ deviant, positive/negative, intelligent/unintelligent, strong/weak, caring/uncaring, interesting/boring, trained/untrained, professional/unprofessional. 
had a margin of error of $+/-4.7 \%$ and found that only $12 \%$ of the sample felt that they would have a "great deal of confidence" in social workers, compared to therapists $(10 \%)$, counsellors $(16 \%)$, psychologists (24\%) and psychotherapists $(18 \%)$. At the other end of the scale, $8 \%$ of the sample stated that they would have "no confidence at all" in social workers (or counsellors), compared to $11 \%$ with therapists, $9 \%$ with psychologists, and $12 \%$ with psychotherapists (SWRB, 2011).

Participants in the Staniforth et al. (2014) study appeared to hold a generally sympathetic view regarding the working conditions of social workers with a majority believing that social workers were hardworking, underpaid and have a stressful job. However, there was a degree of ambivalence reported in regards to the public's beliefs about the trustworthiness of social workers, with less than half of the participants agreeing to the statement "in general the public trusts social workers".

\section{Methodology}

A full description of methodology for the first study and development of the original measurement tool is available in Staniforth et al. (2014). A brief summary of the first public study is detailed here, with a more comprehensive description of the social workers' study, which has not been previously reported upon. Both studies received ethical consent from The University of Auckland Human Participants Ethics Committee.

\section{Design}

Public Study: The prior study was conducted by use of phone interviews (contracted to a private research company) to survey 386 people through Aotearoa New Zealand. Data was collected on a quota-based system to reflect the national population. The response rate was $30 \%$.

Social Workers' Study: An email invitation was sent to members of the Aotearoa
New Zealand Association of Social Workers (ANZASW), inviting them to take part in an anonymous online survey asking them about their perceptions of how social work and social workers were viewed by the public. From this invitation, 403 people responded. (It was not possible to determine the response rate as those who were emailed were encouraged to forward the invitation to other social workers who may not have been members of ANZASW).

\section{Survey}

Public Study: This survey design was informed by a literature review. There were 17 questions in the survey tool, with a mixture of Likert response questions, yes/no and open questions. Respondents were asked for their views in regards to 'first words that come to mind when you hear the words social work', trust in social workers, stressfulness of the job, remuneration, registration, education and types of activities that social workers do. Respondents were also asked if they would like a family member to become a social worker and beliefs about how the profession could improve its image. Demographic questions were asked in regards to gender, age, ethnicity, residence (location and geography) and if the respondent or anyone in their family had used social work services previously.

Social Workers' Study: The survey tool in this study was developed based on the same questions that had been asked in the public study. Additional questions were asked in regards to social workers' views on media portrayal, stigma and if they were proud to be a social worker. Demographic questions were asked in regards to gender, age, ethnicity, area of social work practice and length of time in social work.

\section{Respondent characteristics}

Public Study: $45.7 \%$ of respondents reported to be male, $54.3 \%$ female, and none as transgendered. In this study $79.5 \%$ were of 
New Zealand European/ Pākehā descent, $5.8 \%$ reported being Māori, $2.3 \%$ being Pacific Peoples and 4.3\% Asian. For full details on age, place of residence and if respondents or their close family members had used social work services, please see Staniforth et al. (2014).

Social Workers' Study: Within the sample, $85.8 \%$ of respondents reported to be female, $14.2 \%$ male, and none as transgendered $(n=351)$. In terms of age, there were only $4.0 \%$ of respondents in the age group of 20 to 30 years, $25.1 \%$ between 31 and 45 and $46.2 \%$ between $46-59$. There were $24.8 \%$ who reported being over 60 years of age $(n=351)$. This is of interest as $71 \%$ of respondents were over the age of 45 . This is consistent with reports of an older demographic being represented in social work (Geoff Pearman, Partners in Change, 2011).

The majority of participants $(\mathrm{n}=349)$ identified as New Zealand European/ Pākehā (74.2\%). Māori comprised 10.6\% of the respondents, with only $0.9 \%$ Pacific Peoples being represented. Asian people made up $1.1 \%$ of the sample, with $11.5 \%$ identifying as of "other" ethnicity. 1.7\% did not wish to respond.

Of those responding to the question about where they worked $(n=299), 54.2 \%$ responded that they worked in a statutory setting, and $37.8 \%$ in a non-government organisation. Eight percent of respondents indicated that they were in private practice with $10.0 \%$ indicating that they were in an "other" category. These included those working in education, being retired, and with many also working in health (not seen as a statutory organisation).

In terms of length of time in social work, these results are consistent to a degree with age. Only $4.0 \%$ indicated that they had been in social work for less than two years, 24.9 $\%$ between three and 10 years, and $42.6 \%$ from 11 to 25 years. $28.6 \%$ indicated that they had been in social work for more than 25 years.

\section{Data analysis}

Both studies: Closed and Likert questions were analysed through SPSS (IBM, 2013). Open-ended questions were analysed thematically.

\section{Public and social worker comparisons}

Statistical tests to ascertain if there were significant differences between public perceptions of social workers and social workers' expectations of how the public perceived social workers were conducted on the four survey questions, requiring respondents in the previous public sample and the current social worker sample to answer on a 5-point Likert scale (e.g. In general: 1) "New Zealanders trust social workers", 2) "social workers in New Zealand work hard", 3) "social workers in New Zealand have a stressful job", 4) "social workers in New Zealand are well paid"). The public respondents were presented with the option to select 'I don't know' as a response for these questions whereas the social worker respondents were not, thus those selecting 'I don't know' were excluded from the analysis of group differences for these four questions. In addition, statistically significant differences in the proportion of respondents across the two groups were also calculated for questions requiring the selection of one or more categorical responses (e.g. expectations about social work roles). Full details about the statistical analyses are available from the authors upon request.

\section{Findings}

Findings are reported here for the social workers' study and then on the comparisons of the two studies.

\section{What is social work and what do social workers do?}

The public group in the previous study was asked, "When you hear the words 'social worker' what is the first phrase that comes into your mind?" The social work group 
was asked "What are three words that you believe come to mind for the public when they hear the words 'social worker'?". There were 221 social workers who responded to this question. Their responses were analysed thematically. The most frequently cited words were 'Child Youth and Family (the name of Aotearoa New Zealand's statutory child protection service) with 81 responses. This was followed by 'helping' (55), 'stealing or removing kids' (41), 'do gooders' (37), 'interfering/busy bodies' (31), 'child abuse or protection' (26), and words to do with it being a difficult or stressful job (19). Table 1 shows responses for social worker and public surveys.

Social workers were asked to respond 'yes' or 'no' to a series of statements about how they thought that the public would see areas of work that social workers may be involved in, and also roles that social workers could undertake. In terms of where participants believed the public saw them working, the most frequent 'yes' responses occurred for 'child abuse and neglect' (99.7\%), 'working with troubled teenagers' (91.1\%), and 'parents and parenting problems' (83.6\%). These top results were followed by 'mental illness and addictions' (75.1\%), 'services for older people' (71.9\%) and 'housing and welfare benefits' (70.8\%). The least cited 'yes' responses were indicated for 'prison and probation work' $(62 \%)$, and finally 'healthadapting to illness' (48\%). Panel A in Figure 1 demonstrates the results for both studies to this question.

Social workers were also asked to report on what they thought the public would say about the roles social workers engage in. In this instance, the most frequently cited 'yes' responses were 'support parents and families' (89.2\%), 'help people get resources' (88\%), and 'do counselling with people' (67.8\%).

Less cited 'yes' responses were given for 'help communities solve problems' (56.5\%), 'speak out against injustice' (54.1\%), and finally 'influence social policy' (27.7\%). Panel B of Figure 1 shows the comparative responses from the public and social work studies.

\section{A question of trust}

Social workers were asked to rate their belief in the statement 'In general New Zealanders trust social workers'. Responses to this question are located in Panel A of Figure 2 alongside the responses provided in the public perceptions study to the same question. Only $0.5 \%$ of social workers 'agreed strongly' that the public trusted

Table 1. What the public thinks of when they hear the words "social worker"

\begin{tabular}{lcll|} 
Response Public & N & Response Social Workers & N \\
\hline Helper & 165 & Children Youth and Family & 81 \\
\hline Meets specific personal need & 42 & Helping & 55 \\
\hline Children/Youth help & 34 & Steal/remove kids & 41 \\
\hline Meets specific community needs & 34 & Do gooders & 37 \\
\hline CYFS/WINZ/Government & 31 & Interfering/busy body & 31 \\
\hline Counsellor/Someone who listens & 22 & Child Abuse/protection & 26 \\
\hline Caring & 13 & Stressful/hard job & 19 \\
\hline
\end{tabular}

Figure 1. Comparisons of public perceptions and social workers expectations of public perceptions regarding the nature of the work social workers engage with.

\section{A: Comparison of Response \% for Areas of Social Work}

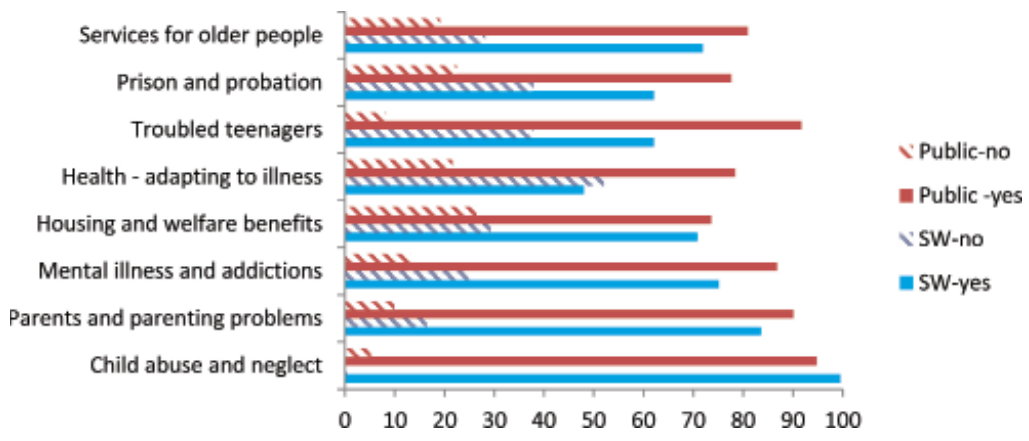

B: Comparison of Response \% for Social Worker Roles

Do counselling with people

Influence social policy

Support parents and families

Help people get resources

Help communities solve problems

Speak out against injustice

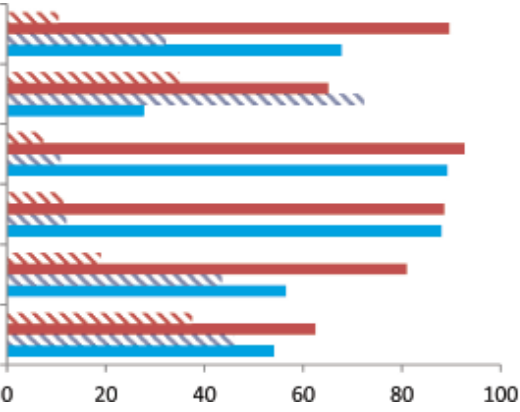

N Public-no

- Public-yes

s SW-no

aW-yes 
social workers, while $38.4 \%$ did 'agree' with this statement. Less than half the respondents believed that the public trusted social workers with $29.8 \%$ indicating a neutral response, $28.8 \%$ disagreeing with the statement, and $2.4 \%$ disagreeing strongly.

\section{Working conditions and remuneration}

Social workers were asked to comment on what the public believed in relation to statements about working conditions and remuneration. Panel B of Figure 2 shows the public and social worker responses to the statement that 'social workers are hard working'. In this instance, $58.9 \%$ of social workers 'believed' or 'believed strongly' that the public would hold this opinion. $12.3 \%$ of the social workers 'disagreed' or 'disagreed strongly' with this statement. Panel C of Figure 2 shows responses for both studies to the statement 'social workers in New Zealand have a stressful job'. Social workers indicated that the public would 'believe' or 'believe strongly' this statement at the rate of $89.6 \%$. Finally, both groups were asked to rate the statement 'the public believes that social workers in New Zealand are well paid'. Results for this are shown in Panel D of Figure 2. In this question, $23.3 \%$ of social workers 'agreed' or 'agreed strongly' with this statement. $37.8 \%$ 'disagreed' or 'disagreed strongly' with this statement, while $38.9 \%$ were neutral.

Figure 2. Comparisons of public perceptions and social workers expectations of public perceptions regarding social worker trust, working conditions and renumeration.

\section{A: Comparison of Response \% to "Social Workers are Trustworthy" B: Comparison of Response \% to "Social Workers are Hard-Working"}

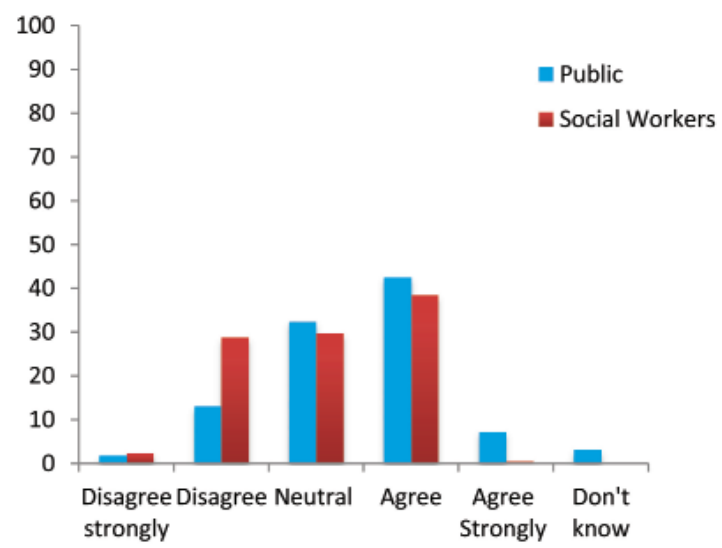

C: Comparison of Response \% to "Social Work is Stressful"

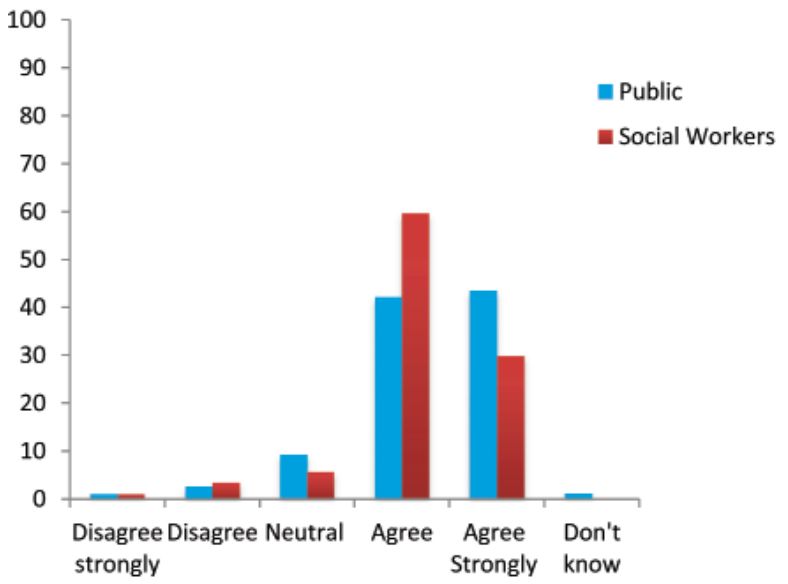

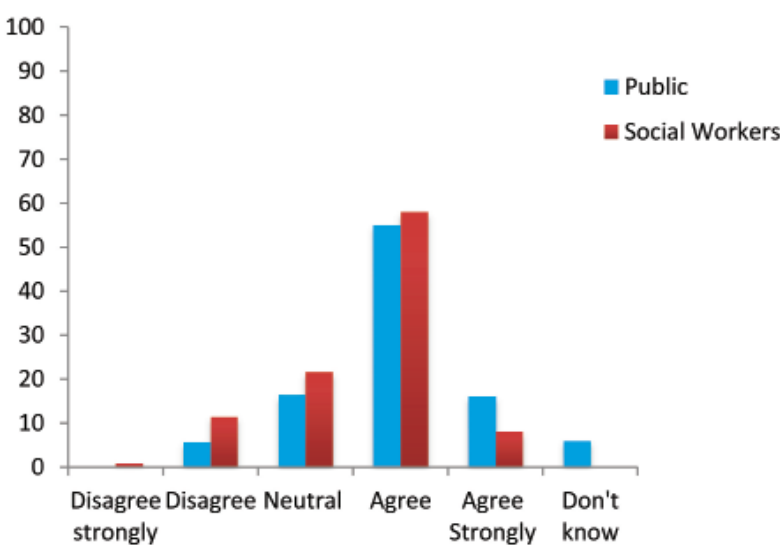

D: Comparison of Response \% to "Social Workers are Well-Paid"

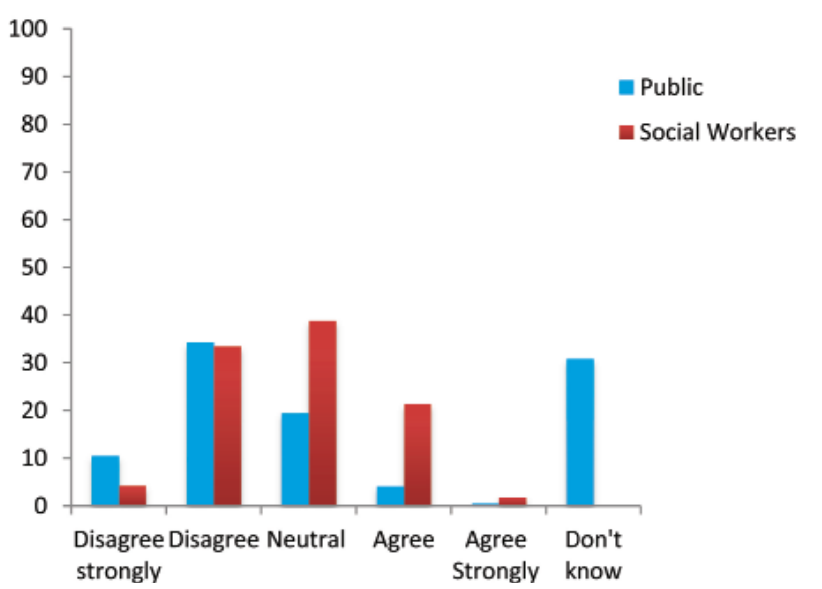




\section{Registration and education}

Both studies explored views on whether the public believed that social workers should be registered 'like doctors, nurses and teachers'. A majority (88.5\%) of social workers answered 'yes' to this statement and $83.3 \%$ of participants in the public study agreed with this statement.

In terms of educational requirements for practising as a social worker, social workers were asked what they thought the public believed the qualifications were, and then what they believed the public thought that they should be. Generally, social workers believed the public thought that they needed a bachelor's degree $(44.4 \%)$, and that is also what they felt the public believed they should have $(64.9 \%)$. Figure 3 shows the answers to these questions and compares them to the public responses.

\section{Other areas}

The social workers were asked two questions 'did they believe that the public would encourage their children or close family member to become a social worker?', and then also 'would you encourage your child or close family member to become a social worker?' Only 25\% of the social work group believed that the public would encourage their child or close family member to become a social worker, but conversely, $68 \%$ of the social work group stated that they would encourage their child or close family member to become a social worker.

There were other questions that were asked specifically of the social work group. Social workers were asked if they believed that there was stigma associated with being a social worker. A resounding $87 \%$ answered yes to this question.

The social work participants were asked how they believed social work and social workers were presented by the media. An overwhelming $88.6 \%$ of the social work group responded that they believed that they were 'not very well presented' or 'presented very badly'. Only $4.1 \%$ believed that they were well- portrayed.

The social work group were asked 'What do you think could be done to improve the image of social work or social workers in this country?' There were 372 people who responded to this question. Several themes emerged out of this open-ended question. The role of the media was seen to be either not used positively, or underutilised. Many respondents suggested that it would be good to have more 'good news' stories in the media, and that educating the public about the different roles of social work would also be useful. Many social workers felt that it would help the image of the profession if registration was compulsory, with protection of title of 'social worker', and that the professional association could do more in

Figure 3. Comparisons of public perceptions and social workers expectations of public perceptions regarding social workers' educational qualifications.

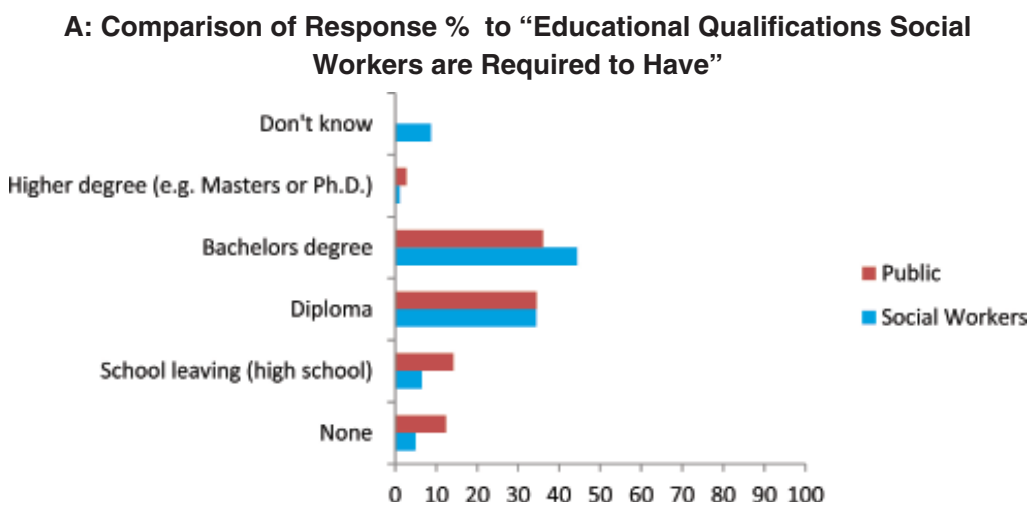

\section{B: Comparison of Response \% to "Educational Qualifications Social Workers Should Have"}

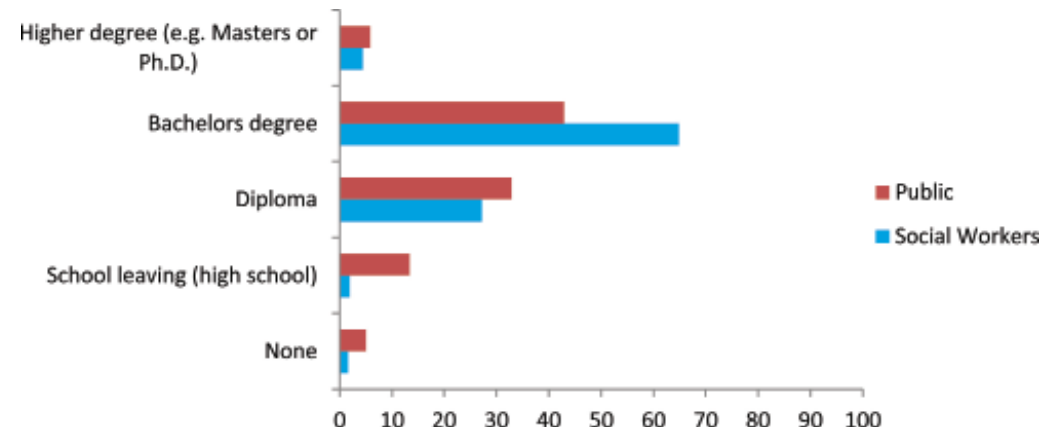


terms of speaking out on social work issues and social policy. The public group were also asked this question, and the themes from both groups will be explored more fully in a future article. Finally, the social work group was asked if they were 'proud to be a social worker'. An astounding 96\% responded yes to this question.

\section{Public and social worker comparisons}

Results regarding what comes to mind when the public hears the words social work, the top seven responses are presented in Table 1 , alongside the public responses from the 2014 study. While many of the themes are similar between the two groups, with both groups maintaining that the public thinks of 'helping or helpers', the social workers perceptions of what they believe the public think appear to be more negative than the public responses. Public responses were more likely to indicate social workers as 'meeting personal and community needs' and 'caring', while social workers were more likely to believe that the public would think first of 'Child Youth and Family', and then also with 'stealing children', being 'do gooders' and 'interfering busybodies'. These ideas were not reflected in the prior public perceptions study.

With regards to public perceptions of where social workers work, the two groups' expectations differed significantly with respect to social worker roles. Compared to social workers' expectations of the public's perceptions, the public respondents were more likely to think that social workers worked in the area of child abuse and neglect, mental illness and addictions, prison and probation services, services for older people and to think they spoke out against injustice, helped communities solve problems, influenced social policy, and be involved in counselling. These differences ranged from 1.41 to 4.86 times more likely (for speaking out again injustice to influencing social policy, respectively). In contrast, social workers were 10 times more likely to expect the public to think social workers worked in child abuse and neglect than the public respondents did (See Figure 1 for these comparisons). Social workers also perceived the public to have lower expectations of social worker trustworthiness, work ethic and job stress than the public actually did, and social workers expected the public to think they were paid more. However, these differences were all fairly small. Figure 2 illustrates these comparisons.

The two groups also had significantly different overall expectations of the public's perceptions of the educational qualifications social workers were required to have and those that the public felt they should have. In comparison to the public respondents' perceptions, the social worker respondents were 1.42 times more likely to think the public expected them to be required to have a bachelor's level qualification. The public respondents' were 2.80 and 2.46 times more likely to expect social workers to be required to have no qualifications or only high school completion (respectively) than social workers expected the public to report. For the basic level of education the public felt that social workers should have, the public respondents were more likely to believe social workers should have no qualifications or only high school completion (3.13 and 8.16 times more likely, respectively) than social workers expected the public to report. The social worker respondents were 2.46 times more likely to believe the public would expect them to have a bachelor's degree (See Panel B in Figure 3). No differences existed in perceptions pertaining to diploma and higher level (e.g. Masters, Doctorate) qualifications for both questions.

\section{Discussion}

There are several points of interest that come from the data. These include perceptions regarding the roles of social work, remuneration, the media and public education. 


\section{Social workers are child protectors}

The public appears to have a fairly good level of awareness of the areas where social workers work. The social workers also believed that this was the case. In these two studies, participants were presented with a category to respond 'yes' or 'no' to each suggested field of practice. As such participants were provided with suggestions about the various roles and tasks of social workers. While the strongest public and social work response rate was agreement that social workers worked with child abuse and neglect (with social workers believing that the public believed this more strongly than did the public group), there was also strong agreement with other roles that social workers are involved in such as supporting parents, and working with troubled adolescents (things also within the remit of child protective services).

These findings are consistent with previous studies on the public perceptions of social work (Condie et al, 1978; Le Croy \& Stinson, 2004) which found a very strong theme in public perceptions of social work as being about child welfare. In the study by Condie and colleagues (1978) it was found that the most cited perceived roles for social workers were child protection, community organizing, and mental health, while Le Croy and Stinson (2004) found that over $90 \%$ of respondents perceived it as appropriate that social work involve a child protector role. What is somewhat surprising is that, in the current study, social workers believe that the public identifies these roles for social work more than the results of the public survey suggested.

\section{Salary}

Another finding that appears consistent with at least two previous studies (Dennison et al 2007; Research Works, 2001) was that social workers were not well remunerated. In both the public and social work studies reported in this paper, a majority of public and social workers were of the belief that social workers were not well paid. This perception is likely to further decrease the status of the profession and in turn have implications for people choosing social work as a career. This is of concern with an aging social worker demographic and the need for an expanding workforce. Earlier studies have suggested that the public believed that altruism and the drive to 'do good' were thought to explain social workers' vocation in the face of low pay and demanding work (Research Works, 2001; Davidson \& King, 2005).

\section{Education and media presentation}

Social workers in this study sensed that there is stigma associated with social work and that they are not particularly well represented by the media. These results are consistent with many previous studies, which have corroborated this belief (Davidson \& King, 2005; Zugazaga, Surette, Mendez, \& Otto, 2006). These responses were strong and again, are likely to impact upon retention and recruitment of social workers into the profession.

Related to media portrayals are the messages, or more significantly, a lack of positive messages, that the public receive from social workers. Both studies reported in this article suggest that one of the ways of improving the public perception is for social workers to become better at educating the public about their roles and mission. These results also confirm findings from previous studies (Comley 1985; Dennison et al. 2007) that indicate a need for better public education from the profession. Dennison et al.'s study also found that the better educated their participants were, the more likely their desire to enter social work as a career.

Of concern is the belief held by both groups in the two studies that the public lacks trust in social workers with less than 50\% agreement in both groups that the public trusts social workers. There are several implications stemming from this perceived lack of trust. While not as severe as the 
finding by Condie et al. (1978) that $98 \%$ of their respondents would not feel comfortable seeing a social worker, a lack of trust would likely impact on service user experience and desire to use social work services. Prospective students may also be less likely to engage on a career path of a profession where there is a perceived lack of trust. These studies did not ask about potential reasons for lack of trust, but negative media presentation, high profile child abuse cases and the concomitant strong association with Child Youth and Family, alongside general ambivalence about child protection (Parton, 2014), seem likely to influence trust levels in the profession of social work. Further study to look at why there is a lack of trust in social workers would be beneficial in order to strategise on how to improve the trustworthiness of social workers in the public estimation.

The overall finding that our social worker participants held a poorer impression of what the public believed, in comparison with the actual public opinions expressed in the prior study has implications for the profession and for social work education. As educators we are aware that social work students receive many mixed messages from the mainstream media, and from social workers themselves, about negative public perceptions of the profession. It is important to confront the concerns raised head on, rather than brush these aside. Within the social work curriculum room must be made to explore public perceptions of media coverage of social work and, most importantly, to analyse this critically not defensively, wherever possible linking discussion to the views and contributions of service users.

With an aging workforce many social workers are nearing retirement age and it is vital that we are able to grow a positive, skilled and confident cohort to take us into the future. Negative messages can influence students coming into schools of social work. Even when students arrive they may receive negative messages given unwittingly by lecturers and field educators. Today's students will be the ones who will have the power to 'be the change they want to be', and it is important that they are not dissuaded from feeling pride in what they do at an early stage of their careers.

While the public perceives social workers more favourably than social workers anticipate, there is still much work to do in terms of getting the message out about who social workers are and what they do. There are still concerns about the trustworthiness of social workers and a lack of clarity about the full range of social work participation in wider fields of practice and social work education and regulation. This requires social workers to raise their public profile, to be active on issues of social justice, but also to work more proactively with many different kinds of news media.

Stanfield and Beddoe (2013, p. 47) have made a case for social workers to 'take advantage of the expertise of media professionals' and to promote public awareness of social work and social issues, perhaps working 'alongside the media to encourage more in-depth reporting of social issues and social work'. Furthermore they recommend that social workers embrace the opportunities provide by social media to give additional voice to social workers and the services in which they deliver services. Social workers can start by communicating more frequently in the public domain about the profession, its values, education and contributions to practice and research in the field of social services.

Other findings of interest include the relationship between social workers' strongly perceived recognition of stigma about the profession and their overwhelming expression of pride about being a social worker. There is also an apparently contradictory finding in both studies in relation to supporting the idea of a child or close family member becoming a social worker. These findings are intriguing, and will be explored in further articles. 


\section{Conclusion}

This article has reviewed the results from a survey of social workers on their beliefs about how they and the profession of social work are perceived by the public, and then compared these results to an earlier study conducted on public perceptions of social work and social workers. Across all survey questions, the only areas where the public respondents' perceptions did not differ significantly from the social worker respondents' expectations of public perceptions were with regards to the need for social workers to be registered, social worker roles in the areas of housing and welfare, supporting teenagers, parents and families, helping people get resources and encouraging children or family members to become social workers. These results demonstrate that social workers appear to have a poorer impression of how they and the profession are perceived by the public in several areas, than the public actually does. Regardless of some of the negative expectations described above, and the strong belief that there is stigma associated with being a social worker, nearly all respondents were proud to be social workers! This apparent contradiction will be explored further in a future article.

\section{References}

Aldridge, M. (1990). Social work and the news media: A hopeless case? British Journal of Social Work, 20(6), 611-625.

Comley, M. (1985). All in a day's work. New Statesman and Society, 109, 21-23.

Condie, C. D., Hanson, J. A., Lang, N. E., Moss, D. K., \& Kane, R. A. (1978). How the public views social work. Social Work, 23(1), 47-53. doi:10.1093/sw/23.1.47

Davidson, S., \& King, S. (2005). Public knowledge of and attitudes to social work in Scotland. Edinburgh, Scotland: Scottish Executive Social Research.

Dennison, S. T., Poole, J., \& Qaquish, B. (2007). Students' perceptions of social work: Implications for strengthening the image of social work among college students. Social Work, 52(4), 350-360.

Franklin, B., \& Parton, N. (Eds.). (1991). Social work, the media and public relations. London, England: Routledge.

Geoff Pearman Partners in Change. (2011). Scoping Report "The Learning Exchange" Aotearoa New Zealand Association of Social Workers. Auckland, New Zealand: Author.

IBM $^{\circledR}$ (2013). IBM ${ }^{\circledast}$ SPSS $^{\circledR}$ Version 22 [Software].
Jones, C. A., Vela, E., Vang, T., \& Walde, B. D. (2006). Perceptions of social work: Undergraduate students assess the profession. The Journal of Baccalaureate Social Work, 12(1), 1-12.

LeCroy, C. W., \& Stinson, E. L. (2004). The public's perception of social work: Is It what we think it is? Social Work 49(2), 164-174.

Lytollis, S. (1996). Making the best of the media spotlight. Social Work Now (5), 15-20.

Parton, N. (2014). Social work, child protection and politics: Some critical and constructive reflections. British Journal of Social Work, 44(7), 2042-2056. doi:10.1093/bjsw/ bcu091

Pollak, O. (1961). Image of the social worker in the community and in the profession. Social Work, 6(2), 106-111. doi:10.1093/sw/6.2.106

Research Works Limited. (2001). Perceptions of social work and social care: report of findings. London: COI Communications, Department of Health.

Social Workers Registration Board (2011). Omnibus survey. Unpublished.

Stanfield, D., \& Beddoe, L. (2013). Social work and the media: A collaborative challenge. Aotearoa New Zealand Social Work, 25(4), 41-51.

Staniforth, B., Fouché, C., \& Beddoe, E., (2014). Public perception of social work and social workers in New Zealand. Aotearoa New Zealand Social Work, 26(2/3), 48-60.

Zugazaga, C. B., Surette, R. B., Mendez, M., \& Otto, C. W. (2006). Social worker perceptions of the portrayal of the profession in the news and entertainment media: An exploratory study. Journal of Social Work Education, 42(3), 621-636. 